\title{
EVALUACIÓN DEL CRECIMIENTO DE Lactobacillus casei Y PRODUCCIÓN DE ÁCIDO LÁCTICO USANDO COMO SUSTRATO EL SUERO DE LECHE DE VACUNO
}

\section{EVALUATION OF Lactobacillus casei GROWTH AND PRODUCTION OF LACTIC ACID USING AS SUBSTRATE THE WHEY OF BOVINE MILK}

\author{
Luis Fernando Escobar, Carlos Andrés Rojas, Germán Antonio Giraldo G. y Leonardo Padilla Sanabria
}

Docentes Programa de Química, Universidad del Quindío

Fecha de recibido: Febrero 3 de 2010

Fecha de aceptado: Junio 9 de 2010

Correspondencia: Laboratorio Diseño de Nuevos Productos, Universidad del Quindío. Av. Bolívar calle 12 norte Armenia Quindío. Correo electrónico: calosandrew@yahoo.com

\section{RESUMEN}

El Lactobacillus casei es un microorganismo que se utiliza como probiótico ya que genera actividad antagónica contra patógenos causantes de desordenes gastrointestinales, debido a su capacidad inmunomoduladora y a cambios de $\mathrm{pH}$ generados por la producción de ácido láctico. Por esta razón, este trabajo se ha enfocado en evaluar la producción del microorganismo y del ácido láctico, adaptando como sustrato un subproducto de la industria láctea (lacto-suero), que es un gran contaminante al vertido a los cuerpos de agua, para esta investigación el lactosuero es desproteinizado y enriquecido con diferentes cantidades de glucosa. Se lograron estandarizar curvas de crecimiento bacteriano en lacto-suero con una producción celular de 5,9x1010 UFC/mL en 75 h, y de ácido láctico de 70,39 y 76,24 g/L en 93 h, con 0\% y 5\% de glucosa respectivamente. Igualmente se estandarizó un proceso de liofilización para conservar el Lactobacillus casei producido durante la investigación. Finalmente, se verificó la pureza de la cepa a través del kit API50CH.

Palabras clave: Lactobacillus casei, Lacto-suero, Ácido láctico, Probióticos, Liofilización, BAL (Bacterias ácido lácticas).

\section{ABSTRACT}

Lactobacillus casei is a microorganism used as a probiotic because it generates antagonistic activity against pathogens that cause gastrointestinal disorders, due to its immunomodulatory capacity and changes in pH produced by lactic acid production. For this reason, this work has focused on evaluating the growth of the microorganism and production of lactic acid using as a substrate a byproduct of the dairy industry (whey) which is a major pollutant when it is discharge into water bodies. For this research, whey was deproteinized and enriched with different amounts of glucose. Standardization of bacterial growth curves in whey was possible, with a production of cells of $5.9 \times 1010 \mathrm{CFU} / \mathrm{mL}$ in $75 \mathrm{~h}$, lactic acid 70.39 and $76.24 \mathrm{~g} / \mathrm{L}$ in $93 \mathrm{~h}$ with $0 \%$ and $5 \%$ glucose respectively. Likewise, a process of liophilyzation was standardized to preserve the Lactobacillus casei produced during this investigation. Finally, we verified the purity of the strain through the API 50CH kit.

Key words: Lactobacillus casei, whey, Lactic acid, Probiotic, lyophilization, BAL (Acid lactic bacteria).

\section{INTRODUCCIÓN}

Los microorganismos entre ellos las bacterias, han sido claves en el enfrentamiento y solución de problemas en la agricultura, alimentación, salud, y como nuevas fuentes de energía y conservación del medio ambiente (González, R. e.t al, . 2002). Dentro de este grupo, se encuentran las "bacterias lácticas" que producen lactato por la fermentación de azúcares simples a un $\mathrm{pH}$ ácido y a un tiempo definido, liberando productos que dan sabor a algunos alimentos. Roukas y Kotzekidou (1998) estudiaron la producción de acido láctico a partir de suero de leche desproteinizado, con una mezcla de células de Lactobacillus casei y Lactobacillus lactis a partir de un cultivo fedbatch, obteniendo buenos resultados; Ding y Tan (2006) usaron cultivos en baches para la producción de acido láctico, a partir de glucosa y lactobacillus casei, obteniendo como respuesta una respuesta de $180 \mathrm{~g} / \mathrm{L}$. En las últimas décadas, el mercado de este tipo de microorganismos ha crecido notablemente a nivel global, debido a sus efectos benéficos para la salud y por la generación de productos secundarios como el acido láctico; el cual es de gran utilidad en la industria cosmética, farmacéutica, textil, alimenticia y últimamente en la generación de polímetros biodegradables (4-8). El ácido láctico es producido comercialmente mediante fermentación con bacterias lácticas homofermentativas, de azucares de maíz, melazas y sueros de leche (Cayré, M. et. Al., 2007), para realizar el proceso de fermentación en el país se requiere de importar el Lactobacillus casei de Estados Unidos o Japón, lo que convierte el proceso en costoso.

El objetivo de este proyecto fue la producción de lactobacillus casei y la determinación de la concentración de ácido láctico, a partir de suero de leche de ganado vacuno, 
por medio de la adecuación de medios alternativos y condiciones de cultivo propicias que permitan alcanzar altas densidades de microorganismos, de manera que puedan ser utilizados en la producción de alimentos funcionales y probióticos.

\section{MATERIALES Y METODOS}

\section{Materia prima}

El suero fue suministrado por la granja lechera "La Maca", ubicada en la zona rural de Filandia (Quindío), vía vereda la Julia, como subproducto del queso molido de leche de ganado Holstein.

\section{Clarificación y adecuación del suero.}

La clarificación y adecuación del suero se realizó con la adición de $\mathrm{CaCl} .2 \mathrm{H} 2 \mathrm{O}$ en concentraciones de 0,005 y $0,02 \%$ de cloruro (Peñuela M, Vargas G, Torres A, Ríos R 2001), para permitir la precipitación de proteínas y lípidos, luego se autoclavó a $121^{\circ} \mathrm{C}$ y 15 psi y se centrifugó a 4500 g el sobrenadante se esterilizó y almacenó a 4 ㅇ․

El proceso de adecuación y clarificación del suero fresco, se realizó para evaluar el crecimiento bacteriano a través de absorbancia en el U.V-vis, a $550 \mathrm{~nm}$.

\section{Caracterización fisicoquímica.}

La caracterización del lactosuero se realizó en estado fresco y clarificado, con el fin de de determinar las variaciones de los componentes del lactosuero en el proceso de clarificación. Se caracterizó por triplicado, en seis muestras diferentes, correspondientes a seis días consecutivos de producción de queso molido. A cada muestra se le determinó: Nitrógeno por el método de Kjendalh. (Método Kjeldahl-GunningArnold. Adaptado griffin 1955). pH con el potenciómetro (IQ240); lactosa se midió de forma indirecta por el método de SHAFFER-SOMOGYI (Dalgaard P, Koutsoumanis K. 2001), ácido láctico por el método de acidez total (Giraldo, G, Talens $P$, Chiralt A, Fito P, 2003), grasas mediante el equipo Det Grass y por el método butirométrico de Gerber (Senthuran, A., et. al., 1999), grados brix por refractometría con un equipo Thermo Electron Corporation, a temperatura constante de 24,5 ㄷ , sólidos solubles por el método derivado de grados Brix, según Giraldo G. (2003). Mediante la fórmula:

$$
\mathbf{X}_{\mathrm{ss}}=\frac{{ }^{\circ} \mathrm{Brix} / 100 * \mathrm{Xw}}{1-{ }^{\circ} \mathrm{Brix} / 100}
$$

Donde

Xss: Fracción másica de sólidos solubles

Xw: Fracción másica de humedad

\section{Medios de cultivo.}

Se utilizó caldo y agar APT, preparado según las indicaciones del fabricante y un medio a base de suero clarificado, cuya composición son $100 \mathrm{~mL}$ del suero y $10 \mathrm{gr}$ de agar agar.

\section{Cepa bacteriana.}

La cepa liofilizada de Lactobacillus casei ssp casei (ATCC 393) (marca REMEL Importada de lenexa USA) se reactivó por rehidratación en caldo APT, incubado a 37 oc durante $48 \mathrm{~h}$. Esta cepa activada se incorporó en esferas de cerámica (CRYOBANK), de acuerdo a instrucciones del fabricante, para la preservación de la cepa en frio.

Preparación de inoculo para cultivo en suero clarificado: se tomaron $10 \mathrm{~mL}$ de caldo APT, al cual se le adicionó una cerámica (CRYOBANK) con Lactobacillus incorporados; se incubó a 37 으 por 24 horas. Luego se tomaron $0.5 \mathrm{~mL}$ del este medio y se diluyó en caldo APT hasta alcanzar una absorbancia de $0.128 \pm 0,006$. A $550 \mathrm{~nm}$.

Evaluación del crecimiento del L. casei en lacto-suero clarificado.

Las cinéticas de crecimiento se realizaron en un medio de cultivo de $20 \mathrm{~mL}$ y una absorbancia de inoculo de 0,128 \pm 0,006 . El pH inicial del medio fue $6,05 \pm 0,05$.

El crecimiento del Lctobacillus casei en el suero clarificado, se determinó por espectrofotometría, peso seco y recuento por dilución en masa. Además se correlacionó la absorbancia y la cantidad de unidades formadoras de colonia (UFC) por ml.

a. Evaluación del crecimiento por espectrofotometría y recuento por dilución en masa: Se tomaron muestras cada $24 \mathrm{~h}$ hasta $172 \mathrm{~h}$, a cada muestra se le midió la absorbancia a $550 \mathrm{~nm}$ y se le realizó diluciones seriadas en base $10(-1$ a -6$)$, que se sembraron en profundidad en agar APT por duplicado, luego, se incubaron por 48 horas a $37^{\circ} \mathrm{C}$ y se realizó el recuento de UFC/ml de medio, además, se utilizó como medio de cultivo suero con adiciones de glucosa, así: lote SM 1 con $0 \%$ de glucosa, lote SM2 con $5 \%$ de glucosa, lote SM3 con $10 \%$ de glucosa y lote SM 4 con $15 \%$ de glucosa.

b. Evaluación del crecimiento por el método del peso seco: se tomaron muestras cada $24 \mathrm{~h}$ hasta 172 horas, se centrifugaron 4,500 g durante $20 \mathrm{~min}$, luego se lavó el precipitado con agua y se centrifugó $x 10$ minutos a la misma velocidad, después se transfirió a crisoles previamente secados y pesados; las muestras se secaron a 110 oC por 3 horas y posteriormente se colocaron en un desecador a temperatura ambiente por $12 \mathrm{~h}$.

\section{Liofilización}

A partir de cultivos de Lactobacillus casei de 69 horas de incubación en caldo APT y suero de leche de ganado vacuno, se realizó el proceso de liofilización, para lo cual se centrifugaron $20 \mathrm{ml}$ de cultivo a $4500 \mathrm{~g}$ por $20 \mathrm{~min}$, el precipitado (L. casei) se lavó con solución salina al $0,9 \%$ y agua destilada estériles, luego, se adicionó agente crioprotector (suero clarificado), las muestras se congelaron entre - 45 y -55 으, posteriormente, se liofilizó a 100 mtorr por $18 \mathrm{~h}$. en un equipo Virtis modelo BENCHTOP 6K, finalmente se almacenó entre 4 - 8 oC.

\section{Evaluación del microorganismo liofilizado.}

El Lactobacillus casei liofilizado se rehidrató con $20 \mathrm{~mL}$ de 
suero clarificado estéril por $1 \mathrm{~h}$. a temperatura ambiente, Luego, se sembró en Agar-APT y Agar-Suero clarificado por el método de dilución en masa. Se incubó por 48 h y se realizó el recuento de células viables. Por último se identificó el microorganismo utilizando el estuche comercial API $50 \mathrm{CH}$ (Biomerieux) (Medio API50CHB/E: sulfato de amonio 2g, extracto de levadura $0,5 \mathrm{~g}$, triptona $1 \mathrm{~g}$, rojo fenol $0,18 \mathrm{~g}$, base mineral M/100 10ml, tampón fosfato $\mathrm{pH} 7,81000 \mathrm{ml}$ ). El kit API $50 \mathrm{CH}$, contiene diferentes hidratos de carbono que permiten identificar los microorganismos de acuerdo con su capacidad fermentativa.

\section{Correlación entre UFC y Absorbancia:}

A partir de la evaluación del crecimiento bacteriano por espectrofotometría y recuento de unidades formadoras de colonia, se realizó una correlación entre estas dos técnicas para generar una ecuación que permita evaluar el crecimiento del Lactobacillus casei por absorbancia y conocer el recuento de microorganismos viables a partir de esta, utilizando las condiciones de esta investigación. Ensayos similares han sido reportados por Paw Dalgaard, Kostantinos Koutsoumanis. (2001).

\section{RESULTADOSY DISCUSIÓN}

\section{Caracterización fisicoquímica del suero fresco y clarificado:}

En la tabla 1 se observan las características físico-químicas del suero fresco y clarificado, las mediciones se realizaron por triplicado en 3 muestras tomadas en diferentes tiempos.

Tabla 1. Caracterización fisicoquímica del suero fresco y clarificado

\begin{tabular}{|c|c|c|c|c|c|}
\hline \multicolumn{2}{|c|}{ Propiedad físico-química } & \multicolumn{2}{|c|}{$\begin{array}{c}\text { Suero de leche } \\
\text { fresco } \\
\text { Valor } \pm \text { SD } \\
\end{array}$} & \multicolumn{2}{|c|}{$\begin{array}{c}\text { Suero de leche } \\
\text { Clarificado } \\
\text { Valor } \pm \text { SD } \\
\end{array}$} \\
\hline \multicolumn{2}{|l|}{$\mathrm{pH}$} & 6,15 & 0,32 & 6,10 & 0,02 \\
\hline \multicolumn{2}{|c|}{ Densidad $(\mathrm{g} / \mathrm{mL})$} & 1,026 & 0,001 & 1,025 & 0,001 \\
\hline \multicolumn{2}{|c|}{ Extracto seco $(\%)$} & 7,06 & 0,32 & 5,37 & 0,16 \\
\hline \multirow{2}{*}{$\begin{array}{r}\text { Contenido } \\
\text { de grasas }\end{array}$} & Det-gras $(\%)$ & 0,26 & 0,04 & Trazas & - \\
\hline & $\begin{array}{l}\text { butirómetro } \\
(\%)\end{array}$ & $\mathbf{0 , 5 0}$ & 0,17 & Trazas & - \\
\hline \multicolumn{2}{|c|}{ Contenido de Nitrógeno (\%) } & 0,22 & 0,02 & 0,11 & 0,01 \\
\hline \multicolumn{2}{|c|}{ Contenid o de proteínas (\%) } & 1,38 & 0,10 & 0,70 & 0,06 \\
\hline \multicolumn{2}{|c|}{ Acidez total (\% ácido láctico) } & 0,99 & 0,18 & 0,91 & 0,06 \\
\hline \multicolumn{2}{|l|}{${ }^{o}$ Brix } & 6,52 & 0,20 & 6,37 & 0,06 \\
\hline \multicolumn{2}{|c|}{ Humedad (\%) } & 93,06 & 0,39 & 94,69 & 0,16 \\
\hline \multicolumn{2}{|c|}{ Sólidos Solubles (\%) } & 7,07 & 0,32 & 6,47 & 0,01 \\
\hline \multicolumn{2}{|c|}{ Contenido de lactosa (\%) } & 4,71 & 0,46 & 4,35 & 0,06 \\
\hline
\end{tabular}

Como se puede observar, los valores de nitrógeno, proteínas y grasas se ven afectadas por el proceso de clarificación, lo que se ve representado en la disminución del porcentaje de extracto seco. Los demás parámetros no presentan diferencias apreciables en su afectación. Respecto al pH se puede observar que se encuentra dentro del rango óptimo para el crecimiento del microorganismo al compararlo con lo reportado por Senthuran et. al., (1999)

Evaluación del crecimiento del $L$. casei en lacto-suero clarificado.

Para evaluar el crecimiento del microorganismo se realizaron mediciones de absorbancia y recuentos en UFC/mL a través del tiempo, de los cuales se obtuvieron las figuras $1 a$. y $1 b$.

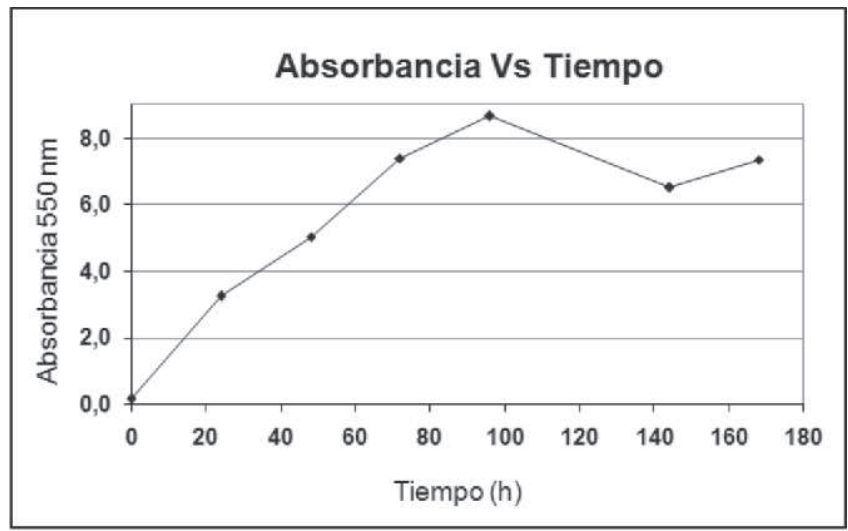

(a)

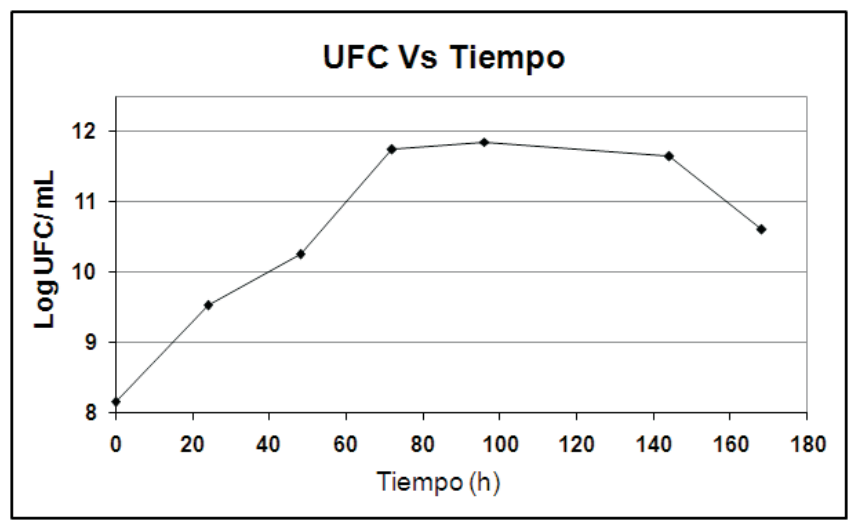

(b)

Figuras 1. Evaluación del crecimiento bacteriano en el tiempo.

Como se observa en la figura el crecimiento del microorganismo vs tiempo, medidos por espectrofotometría (figura 2a) y en el recuento estándar en placa (figura $2 b$ ). Ambos resultados llegan a un pico máximo de crecimiento a las 96 horas, aunque, el crecimiento en la figura $2 b$ en el rango de las 72 y 96 horas ya no es de forma exponencial; a partir de las $96 \mathrm{~h}$ se aprecia un disminución en la absorbancia y de el recuento de microorganismos vivos. Además en la figura $2 \mathrm{~b}$ se observan tres de las cuatro fases del crecimiento de poblaciones bacterianas reportado por la literatura (Tortora G, Funke B, Case C. 2007); fase de crecimiento exponencial, estacionaria y muerte; la fase de latencia no se aprecia debido a que el L. casei se encontraba adaptado al medio (Berenson, M, Levine D. 1983). También se aprecia 
que las mediciones por espectrofotometría en la fase de muerte no se correlacionan con el recuento por UFC debido a que la muerte de los microorganismos genera mayor turbidez por ruptura de las células del mismo.

\section{Correlación entre las UFC y absorbancia.}

En la figura 3, se observa la correlación de las UFC y la absorbancia para el crecimiento del microorganismo hasta las $72 \mathrm{~h}$, se decidió trabajar hasta este tiempo, debido a que coincide con el crecimiento exponencial del microorganismo y no se encuentra cerca de la fase estacionaria, que se inicia a partir de las $96 \mathrm{~h}$, esto nos garantiza una viabilidad adecuada de los microorganismos como también recuentos entre 109 y 1010 UFC/mL que son los recomendados para liofilización.

Esta correlación permite determinar el recuento indirecto de L. casei a través de espectrofotometría, utilizando la ecuación de la línea recta, bajo las condiciones descritas en este trabajo.

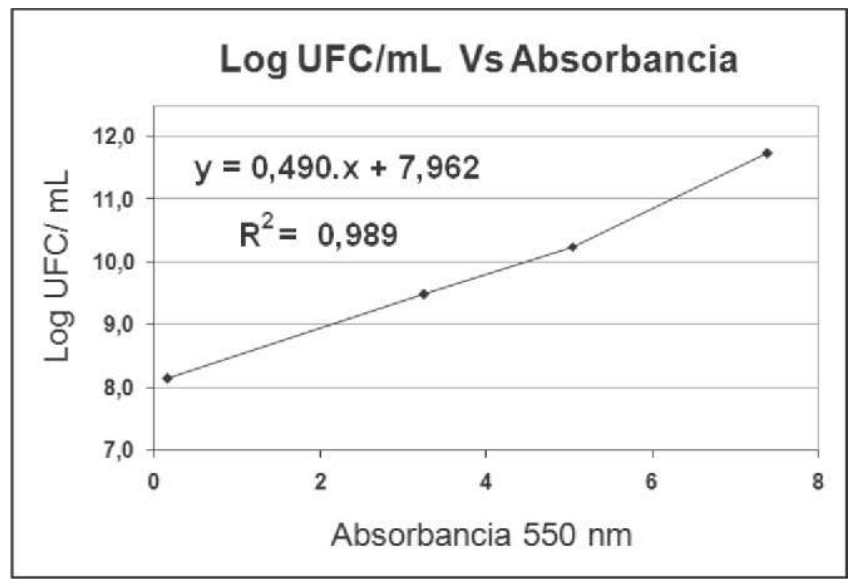

Figura 2. Correlación entre UFCy la absorbancia.

Al aplicar el modelo de regresión lineal, se obtuvo la ecuación (1):

$$
\log [\mathrm{UFC} / \mathrm{mL}] .=0,490[\text { Abs } 550 \mathrm{~nm}]+7,962 \text { (1) }
$$

Con un coeficiente de correlación (R2) de 0.989, el cual es comparable con el rango de $\mathrm{R} 2=0.904-0,998$ obtenido por otros autores con curvas realizadas para microorganismos (Roukas, T. Kotzekidou, P. (1998). Este valor además es muy cercano a la unidad, siendo 1 el mayor valor de correlación para este tipo de figuras (Urribarrí, L. 2004), lo cual confirma que el método de correlación propuesto es viable para la cuantificación de L. casei en lacto-suero clarificado bajo las mismas condiciones de cultivo reportadas en este trabajo.

Consumo de azúcares reductores y la producción de ácido láctico en medios modificados y sin modificar.

Se midieron la concentración de azucares reductores y de acides total, y se correlaciono con la concentración de ácido láctico (por duplicado) a través del tiempo durante el proceso fermentativo, por el método de SHAFFER-SOMOGYI. En el trabajo se observaron los siguientes comportamientos en las figuras 3 de A a D:

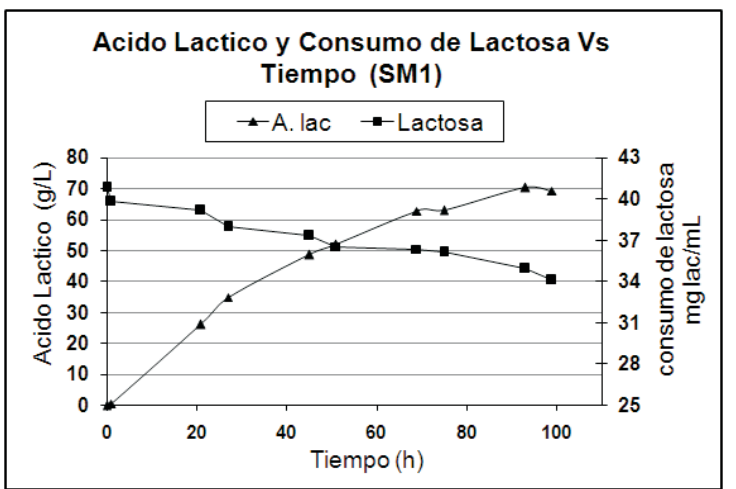

(a)

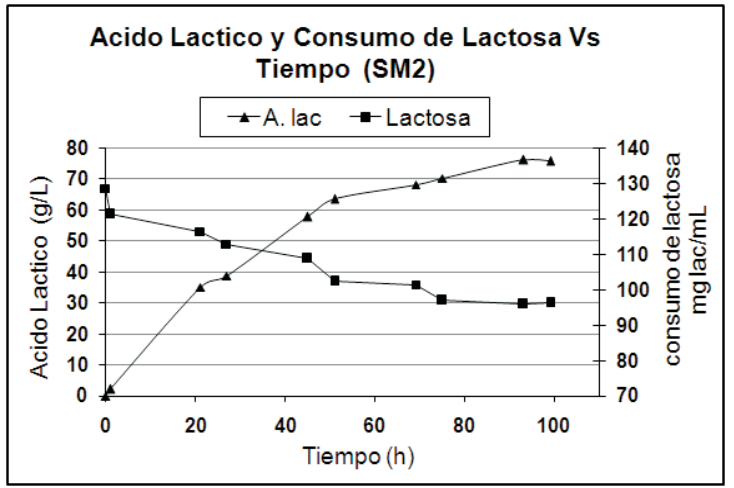

(b)

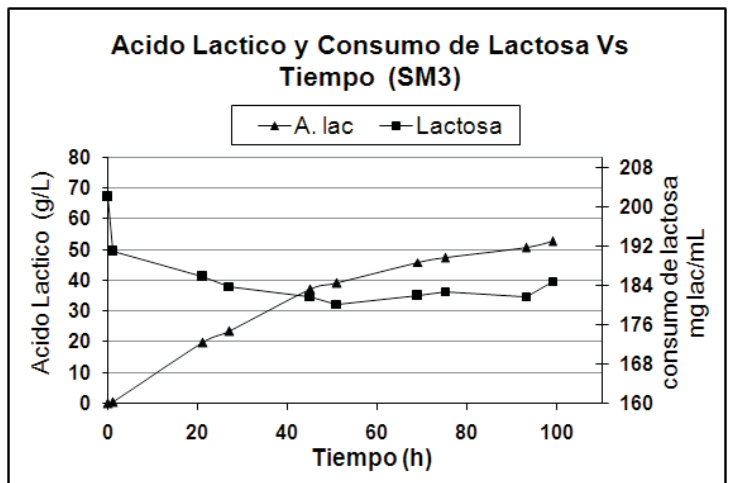

(c)

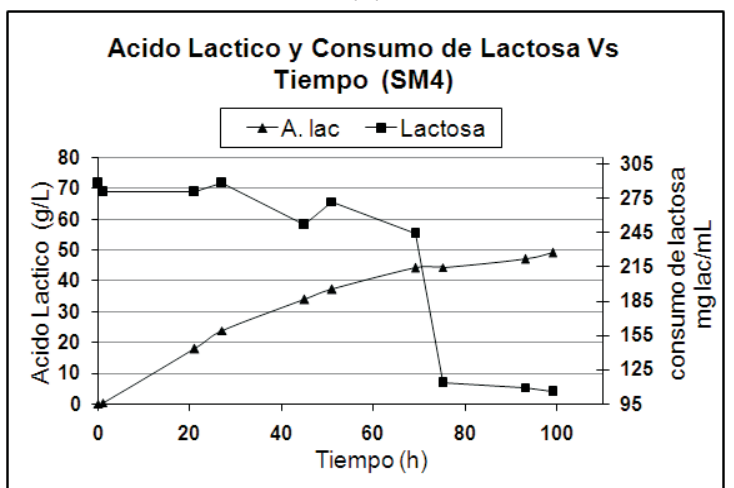

(d)

Figura 3. Conversión de sustrato en ácido láctico (a, b. c, d). 
En la figura 3 se evidencia el consumo de azúcares reductores (expresado como lactosa) y la producción de ácido, expresado como ácido láctico por parte de L. casei en los diferentes medios modificados por adición de glucosa $(0,5$, 10 y $15 \%$ respectivamente). Como se puede observar, en todos los medios hay una disminución en la concentración de los azúcares reductores y un aumento en la concentración de la acidez total por el proceso fermentativo del L. casei, pero a pesar de esto los azúcares remanentes son muy altos especialmente en los medios enriquecidos (SM2, SM3 y SM4). Por el comportamiento anterior podemos afirmar que no es necesario realizar adiciones de azúcares reductores al suero de leche para un óptimo crecimiento del Lactobacillus casei. También es importante resaltar que la medición de la lactosa (azúcar reductor) se realizó por el método de SHAFFER-SOMOGYI, el cual determina la concentración de azúcares reductores, por lo anterior, se evidencia valores diferentes de azúcares en todas las gráficas al tiempo cero, los cuales pueden ser causados probablemente por errores experimentales. El análisis de acido láctico también se puede realizar a través de la técnica de HPLC utilizando la columna (TAG), y teniendo en cuenta las curvas de calibración que previamente se realizaron utilizando concentraciones en el rango de 3-1000 mg / L de ácido Lláctico y 0.5-160.8 mg / L para d-ácido láctico, la fase móvil debe estar constituida de metanol en medio acido, con ello los límites de detección (LD) se alcanzan experimentalmente a 0,2 y 0,5 mg / I de L-ácido láctico y 0,4 y 1,3 mg / L para el dácido láctico, respectivamente.

\section{Producción de ácido expresado como ácido láctico.}

La figura 4, presenta los resultados obtenidos de la cinética fermentativa de suero clarificado que se expresa en $\mathrm{g} / \mathrm{L}$ de ácido como ácido láctico.

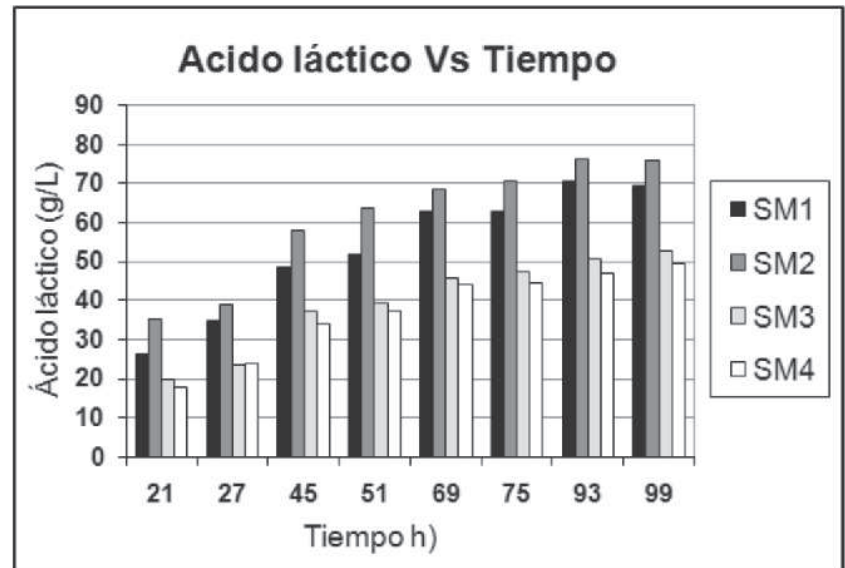

Figura 4. Producción de ácido expresado como ácido láctico.

La mayor producción de acidez total es de 76,24 y 70,39 g/L en las cinéticas $S M 2$ y SM1 respectivamente a las 93 horas de fermentación, notándose una estabilidad a las 99 horas. En la literatura se han reportado producción de acido láctico de 28,8 g/L en la universidad de Antioquia (Jiménez, D. 2002), utilizando $L$. casei cultivado en suero enriquecido, $46 \mathrm{~g} / \mathrm{L}$ por Roukas y Kotzekidou (1998) quienes utilizaron suero desproteinizado y enriquecido, usando una mezcla de cepas de L. casei y Lactococus lactis libres; en la universidad de Zulia
(Venezuela) (Urribarrí, L. 2004) alcanzaron 13,02 g/L utilizando $L$. helveticus en suero de leche desproteinizado y suplementado, (Coudeyras S, Marchandin H, Fajon C, and Forestier C. 2008) alcanzaron una máxima producción de ácido láctico en $210 \mathrm{~g} / \mathrm{L}$ utilizando $L$. casei, cultivado en medio de formulación propia. Es de anotar que cada investigación aquí referenciada, utilizó metodologías diferentes para la determinar el ácido láctico; esta investigación partió del método de acidez total, el cual puede generar una variación en los valores de ácido láctico respecto a lo reportado por otros autores, también es importante destacar que el lactobacillus casei está clasificada como una bacteria homofermentativa lo que indica que su principal producto de la fermentación es ácido láctico (García, M. Uruburu, F. 2003). Los resultados de acides total se expresan como ácido láctico solamente, teniendo en cuenta que la leche y el suero tienen a la lactosa como único azúcar reductor en su composición.

Al comparar la figura $1 \mathrm{~b}$ y la figura 4 se puede concluir que existe una alta correlación entre el crecimiento del Lactobacillus casei y la producción de acido láctico a las 99 horas, tiempo en el cual se observan los mayores picos de crecimiento y producción respectivamente.

\section{Producción de $L$. casei a partir de suero de leche clarificado.}

En la figura 5 se observa la producción de L. casei en el tiempo utilizando la técnica de peso seco.

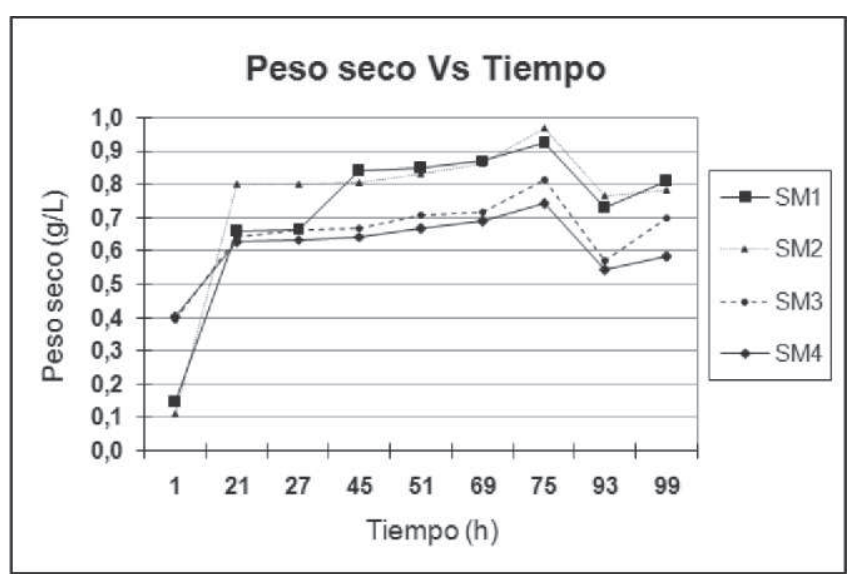

Figura 5. Evaluación del crecimiento bacteriano por peso seco.

En esta figura se observa el comportamiento del crecimiento del Lactobacillus casei, medido a través del peso seco en los cuatro medios de cultivo (SM1, 2, 3 y 4), donde se evidencia un crecimiento constante del microorganismo representado por el aumento de peso seco en el tiempo, todos los medios presentaron un comportamiento similar, aunque, en los medios SM1 y SM2 se obtuvieron mayores valores de peso seco $(0,9238$ y $0,9700 \mathrm{~g} / \mathrm{L}$, respectivamente) a las $75 \mathrm{~h}$ de crecimiento. Esta misma tendencia se observo en las cinéticas de crecimiento medidas por espectrofotometría y recuento de UFC. (Véase Figura 1a y 1b). Si se comparan estos resultados con los obtenidos por Ding et. Al., (2006), los que 
reportan una cantidad de 4,3 g/L, utilizando medios de formulación propia y reactor alimentado, se puede afirmar que a pesar de que el lacto-suero clarificado produce menores cantidades de microorganismos, este proceso es aceptable, debido a que se está utilizando un producto considerado de desecho y una metodología de fermentación diferente.

\section{Conversión de las absorbancias a UFC/mL de las cinéticas de crecimiento SM}

Como se describió en la metodología, las cinéticas de crecimiento del Lactobacillus casei se determinaron a través de diferentes técnicas (espectrofotometría, recuento por dilución en masa y peso seco). Con los datos de absorbancia y la ecuación (1) se generó la conversión de absorbancia a $\mathrm{UFC} / \mathrm{ml}$, como se evidencia en la figura 6 .

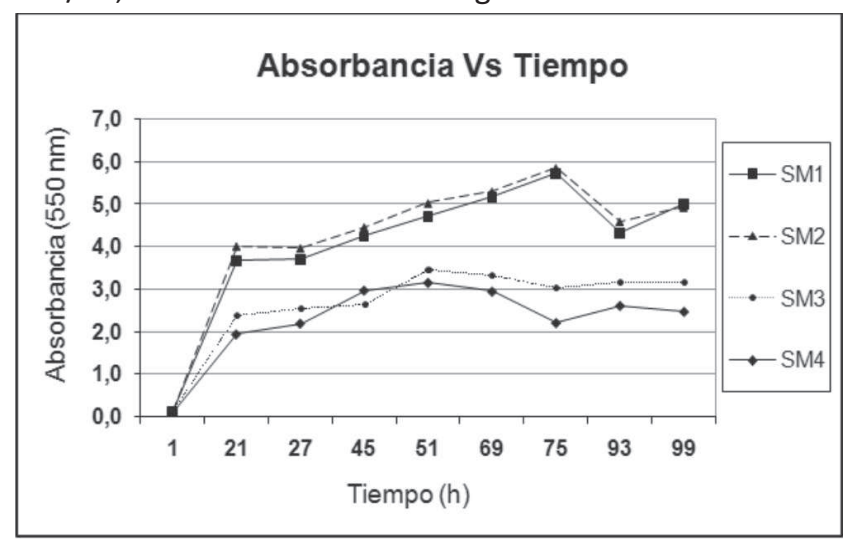

(a)

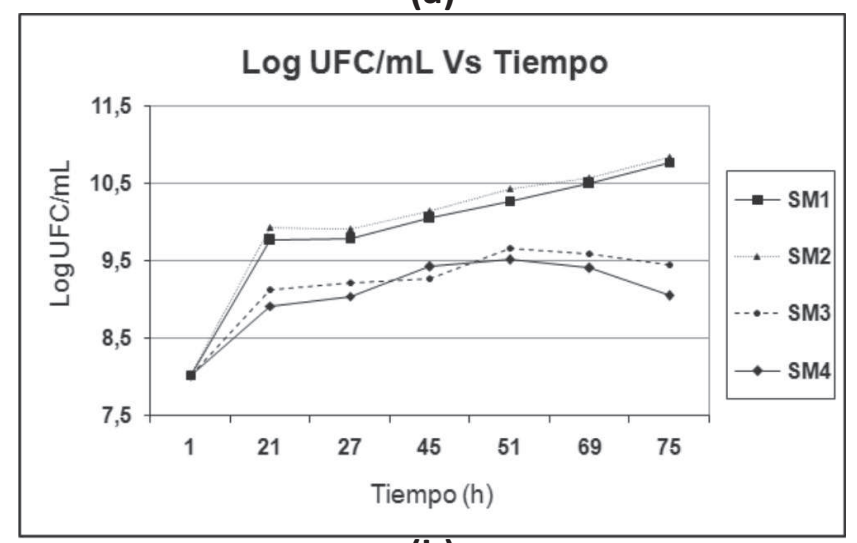

(b)

Figura 6. Evaluación del crecimiento bacteriano por espectrofotometría y conversión en UFC/mL.

En la figura, la curva de conversión de la absorbancia a log UFC/mL, evidencia un crecimiento constante del microorganismo en los diferentes medios SM, al igual que con el peso seco los medios SM (en 1 y 2 pero no se ve constante en 3 y 4 ). Hay que tener en cuenta que sólo se convirtieron los datos hasta las 75 horas de fermentación ya a partir de este tiempo no se garantiza la viabilidad de las células de acuerdo al modelo de crecimiento mostrado en la figura $1 b$.
Finalmente, con los valores obtenidos, se puede decir que las cinéticas SM3 y SM4 muestran los más bajos resultados en cuanto a la producción de L. casei, debido, posiblemente a un proceso de deshidratación de las célula por la alta concentración de azúcares en el medio, lo que ejerce una fuerte presión osmótica sobre el microorganismo, inhibiendo su crecimiento y tal vez provocando su muerte.

\section{Liofilización del microorganismo.}

Tomando como base el modelo de crecimiento del $L$. casei según la figura 1 b, el proceso de liofilización se llevó a cabo a partir de un cultivo de $69 \mathrm{~h}$ de crecimiento con el fin de garantizar la viabilidad de las células y un recuento celular entre $10^{9}$ y $10^{10} \mathrm{UFC} / \mathrm{mL}$, el cual se ha reportado como el rango ideal para la conservación de los microorganismos por liofilización. (Coudeyras S, Marchandin H, Fajon C, and Forestier C. 2008). Las cepas obtenidas durante la fermentación se sometieron a liofilización para lograr prolongar su vida de almacenamiento y así contar con la viabilidad del microorganismo por más tiempo.

Además, de producir el lactobacillus casei y de utilizar el suero de la leche de ganado vacuno como medio para el crecimiento del microorganismo, se decidió, liofilizarlo utilizando como crio-preservante el mismo suero, como una fuente alterna de conservación, ya que uno de los principales problemas que se tiene en la producción de probióticos, es la conservación. Como se puede evidenciar en los resultados obtenidos (véase tabla 2), el suero de leche da ganado vacuno clarificado, podría ser utilizado como criopreservante alternativo para este tipo de microorganismo.

Evaluación del recuento del microorganismo antes y después de liofilizado.

La tabla 2 muestra la viabilidad de los microorganismos en el proceso de liofilización.

Tabla 2. Recuento del Lactobacillus casei.

\begin{tabular}{ccccc}
\hline & $\begin{array}{c}1 \\
\text { UFC } \times 10^{9} / \\
\mathrm{mL}\end{array}$ & $\begin{array}{c}2 \\
\text { UFC } \\
\times 10^{9} / \\
\mathrm{mL}\end{array}$ & $\begin{array}{c}\text { Promedio } \\
\text { UFC } \\
10^{9} / \\
\mathrm{mL}\end{array}$ & $\begin{array}{c}\% \text { de } \\
\text { células } \\
\text { viables }\end{array}$ \\
\hline $\begin{array}{c}\text { Conteo ANTES } \\
\text { de Liofiliza-ción }\end{array}$ & 47 & 49 & 48 & 100 \\
$\begin{array}{c}\text { Conteo } \\
\text { DESPUÉS de } \\
\text { Liofiliza-ción }\end{array}$ & 45 & 45 & 45 & 94 \\
\hline
\end{tabular}

Para evidenciar la viabilidad de los microorganismos después de la liofilización, se realizó un conteo de UFC antes y después del mismo, obteniéndose una viabilidad del 94\% (véase tabla 2 ), siendo un porcentaje de supervivencia muy bueno, ya que lo recomendado es entre un $50-80 \%$ para microorganismos (González, R. et al. 2002 y García, M. Uruburu, F. 2003). Finalmente se corroboró la pureza de la cepa de Lactobacillus 
casei, después del proceso de liofilizado a través del estuche comercial API $50 \mathrm{CH}$ (Biomerieux), utilizándose el software Apiweb stand aloneV1.2.1 referencia 40012, arrojando un resultado del $99 \%$ de certeza sobre la cepa que se cultivó es Lactobacillus casei.

\section{CONCLUSIONES}

Se logró estandarizar un método de cultivo para $L$. casei utilizando como base el suero de leche de ganado vacuno clarificado.

El lacto-suero clarificado sin adición de glucosa, permitió el crecimiento de Lactobacillus casei en niveles de $0.9238 \mathrm{~g} / \mathrm{L} \mathrm{y}$ $5,9 \times 10^{10} \mathrm{UFC} / \mathrm{mL}$ en un periodo de incubación de 75 horas y una producción de 70,39 g/L de ácido expresado como ácido láctico a las 93 horas.

Se obtuvo la ecuación $\log [\mathrm{UFC} / \mathrm{mL}]=0,490$ [Abs $550 \mathrm{~nm}]+$ 7,962 con un coeficiente de correlación de 0,989 al relacionar las UFC y la absorbancia, en un período de 75 horas

No es necesario la adición de azucares al lacto-suero para producir el Lactobacillus Casei, lo que permite utilizar este producto de desecho clarificado sin ningún tipo de modificación.

\section{BIBLIOGRAFÍA}

1. González, R. et al. (2002) Aseguramiento de la calidad en las Colecciones de Cultivos Microbianos. Centro Nacional de Sanidad Agropecuaria CENSA, la Habana Cuba.

2. Cayré, M. et al. (2007) Selección de un Modelo Primario para Describir la Curva de Crecimiento de Bacterias Lácticas y Brochothrix thermosphacta sobre Emulsiones Cárnicas Cocidas. Información Tecnológica. 18 (3): 23-29.

3. Wilhelm H Holzapfel, Petra Haberer, Rolf Geisen, Johanna Björkroth, and Ulrich Schillinger. (2001) Taxonomy and important features of probiotic microorganisms in food and nutrition. Am J Clin Nutr; 73 (3) 65-73.

4. Vargas, M, et al. (2004) Producción de Microorganismos Probióticos como Aditivo para Alimentos Concentrados para Ganado Vacuno (Primera Parte). Revista de ingeniería, 20: 23 - 33.

5. Rodríguez J. (2001) Obtención de Cepas de Lactobacillus, su Caracterización (invitro) como Potenciales Prebióticas.Tesis Magister Universidad de los Andes. Mérida, Venezuela..

6. Senthuran A., et al. (1999) Lactic acid production by immobilized Lactobacillus casei in recycle batch reactor: a step towards optimization. Journal of Biotechnology. 73: 61-70.

7. Peñuela M, Vargas G, Torres A, Ríos R (2001) Evaluación de medios de cultivo preparados a partir de suero de leche enriquecido, para la producción de ácido láctico, con Lactobacillus plantarum y Lactobacillus casei. Revista Facultad de Ingeniería Universidad de Antioquia. No. 24 p. 35-39.

8. Jiménez, D. (2002) Formulación, Elaboración y Preservación de Quesos. Universidad del Quindío. Facultad de Ciencias Agroindustriales. Planta Piloto de Alimentos (documento interno),

9. Bernal, I. (1993) Análisis de alimentos. Bogotá Colombia. Editorial Guadalupe.

10. ASSOCIATION OF OFFICIAL ANALYTICAL CHEMISTS (A.O.A.C) (1997) “Official Methods of Analysis”. 16th Ed. 3rd Revision.

11. Casado, P. (1991) Guía para el Análisis Químico de la Leche y los Derivados Lácteos. Madrid, España. Ediciones Ayala. 7985.

12. Giraldo, G, Talens P, Chiralt A, Fito P, (2003) "Influence of sucrose solution concentration on kinetics and yield of mango osmotic dehydration" USA, Journal Of Food Engineering Elsevier Academic Press, 1 (58) 33 - 43. 
13. Dalgaard P, Koutsoumanis K. (2001) Comparison of maximum specific growth rates and lag times estimated from absorbance and viable count data by different mathematical models. Journal of Microbiological Methods. 43: 183-196

14. Senthuran, A., et al. (1999) Lactic acid production by immobilized Lactobacillus casei in recycle batch reactor: a step towards optimization. Journal of Biotechnology. 73: 61-70.

15. Varela, G. (2002) Fisiología y Metabolismo Bacteriano. Uruguay, Editorial Cefa.

16. Tortora G, Funke B, Case C. (2007) introducción a la microbiología. Buenos Aires. Editorial panamericana. 176-77.

17. Berenson, M, Levine D. (1983) Estadística para Administración y economía. México, D.F. Editorial Interamericana. 482

18. Roukas, T. Kotzekidou, P. (1998) Lactic acid production from deproteinized whey by mixed cultures of free and coimmobilized Lactobacillus casei and Lactococcus lactis cells using fedbatch culture. Enzyme and Microbial Technology. 22: 199-204.

19. Urribarrí, L. (2004) Producción de acido láctico a partir de suero de leche, utilizando Lactobacillus helveticus en cultivo continuo. Revista Científica. Universidad del Zulia. 14: 4.

20. Ding, S. Tan, T. (2006) L-lactic acid production by Lactobacillus casei fermentation using different fed-batch feeding strategies. Process Biochemistry. 41: 1451-1454.

21. Coudeyras S, Marchandin H, Fajon C, and Forestier C. (2008) Taxonomic and Strain-Specific Identification of the Probiotic Strain Lactobacillus rhamnosus 35 within the Lactobacillus casei Group. Appl Environ Microbiol. 74(9): $2679-89$.

22. García, M. Uruburu, F. (2003) la conservación de cepas microbianas. (memorias seminario interno) Valencia, editorial Universidad de Valencia. 